\title{
Effect of Using Polymer Buffer on Efficiency of Crude Oil Recovery by Ionic Liquids
}

\author{
Omer A. Omer ${ }^{1}$, Mostafa M. Kinawy ${ }^{1,2}$, and Mohammed A. Khamis ${ }^{1}$ \\ ${ }^{1}$ Petroleum and Natural Gas Engineering Department, College of Engineering, King Saud University, \\ Saudi Arabia \\ ${ }^{2}$ Mining and Petroleum Engineering Department, Faculty of Engineering, Al-Azhar University
}

\begin{abstract}
Ionic liquids have attracted attention in lowering the interfacial tension between oil and water. Several researches were conducted on these materials and possibility of using them in enhanced oil recovery. In this paper, the effect of using a polymer buffer behind a slug size of ionic liquid during flooding was investigated. Ionic liquid solution was prepared with suitable concentration and salinity. Partially Hydrolyzed Polyacrylamide Polymer (HPAM) was used in preparing polymer solutions. Core flooding runs were performed using slug sizes of ionic liquid followed by polymer buffers having different slug sizes, polymer concentrations, salinities, temperatures and injection rates. The results showed that an injection of a polymer buffer after a slug size of ionic liquid increased the amount of the produced oil significantly. The larger polymer buffer slug size, the larger amount of produced oil. Increasing of salinity and injection rate greatly affect polymer efficiency in the improvement of oil recovery. Rising of polymer concentration may plug the pores and as a result, the amount of oil recovery is not a considerable. Although, increasing of temperature decreases oil viscosity and enhances ionic liquid efficiency, the temperature accelerates polymer thermal degradation and consequently lowers the ultimate oil recovery. High injection rate causes mechanical polymer degradation and displacing fluid bypass over oil, consequently low oil recovery can be obtained.
\end{abstract}

\section{INTRODUCTION}

Polymers are widely used as chemicals in oil industry especially in oil recovery and it is characterized by availability and solubility in water. Polymer flooding is a very mature method with more than 40 years of applications(Abidin, Puspasari et al. 2012). It has been proven that they are effective in recovering unswept oil by improving the mobility ratio(Abidin, Puspasari et al. 2012). There are three potential ways in which polymer flooding makes the oil recovery process more efficient(Abidin, Puspasari et al. 2012):

- Through the effects of polymers on fractional flow.

- By decreasing the water/oil mobility ratio.

- By diverting injected water from zones that have been swept.

The viscosity of a polymer solution is a measure of how "thick" a fluid is and how to resist to flow. For example, honey is characterized as being "thicker" and more viscous than water. The viscosityimproving power of a polymer depends on the size and extension of the polymer molecule in a certain aqueous solution(Sorbie 1991). Due to many reasons, the measured viscosity of a polymer solution in a viscometer and the effective viscosity of the polymer solution that is measured during flow through porous media often have different values. Different types of polymers that succeed to accommodate the wide variety of conditions encountered in oil fields over the world include the following:

\section{- Polyacrylamides}

Always, a synthetic polymer means polyacrylamides. A variety of these are produced by many manufactures. Partially hydrolyzed polyacrylamide (HPAM) is one of the polyacrylamide group(Abidin, Puspasari et al. 2012). Figure1.a shows the structure of the polyacrylamide.

\section{- Xanthan Gum/Biopolymer}

Xanthan gum is a polysaccharide or usually called as biopolymer. The biopolymer is an extracellular slime, which forms on the surface of the cells. The fermented broth is pasteurized to prohibit the microbes and precipitated from the broth by alcohol, then concentrated(Abidin, Puspasari et al. 2012). The structure of the Xanthan gum is shown in Figure1.b. 


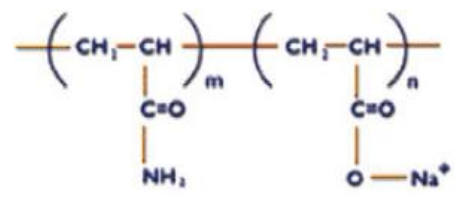

(a)

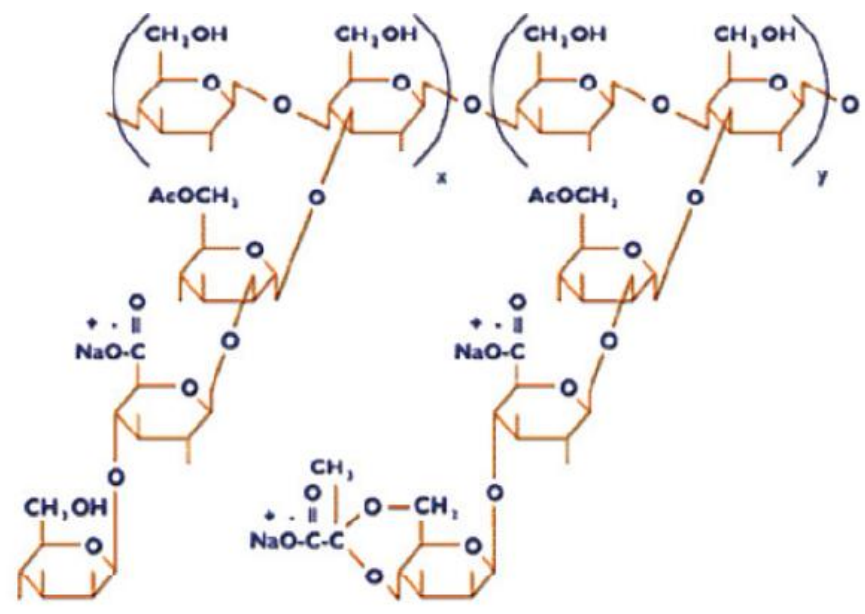

(b)

Figure1. Structure of (a) Polyacrylamide; (b) Xanthan(Abidin, Puspasari et al. 2012).

Moffitt and Mitchell(Moffitt and Mitchell 1983) stated that a commercial polymer flood was developed in North Burbank during the 1980s, demonstrating that this enhanced oil recovery method may still have potential to increase oil recovery in mature basins(Alvarado and Manrique 2010).Muskat(Muskat 1949) first pointed out that the fluid mobilities would affect water flood performance. In 1949-1950, Stiles(Stiles 1949) used the permeability and the capacity distribution in waterflood calculations. Dykstra and Parsons(Dykstra and Parsons 1950) showed that the effect of permeability variation and mobility ratio on recovery. Aronofsky and Ramey(Aronofsky 1952; Aronofsky and Ramey Jr 1956) discussed the mobility ratio and its influence on flood patterns during water encroachment in 1952 and on injection and production histories in a five-spot water flood in 1956. In 1954, Dyes et al.(Dyes, Caudle et al. 1954) presented studies of the influence of mobility ratio on oil production after breakthrough. After that, Caudle, Wite and Barnes (Caudle and Witte 1959; Barnes 1962) suggested improving waterflood sweep efficiency by increasing water viscosity. However, it was not until 1964 that Pye and et al.(Pye, Gogarthy et al. 1964) and Sandiford(Sandiford 1964) established that the mobility of water used in waterflooding can be reduced efficiently by adding small amounts of a water soluble polymer.

For many years, HPAM degradation has been studied. Early study, HPAM viscosity is HPAM viscosity affected by $\mathrm{NaCl}, \mathrm{CaCl}_{2}$ and $\mathrm{MgCl}_{2}$, and HPAM was very sensitive to divalent ions(Mungan 1972). After that, many studies found same results (Maerker 1975; Ward and Martin 1981; Ryles 1988). Therefore, Needham and Doe stated that the most successful field applications of polymer flood were carried out in low-salinity reservoirs(Needham and Doe 1987). Additional to the previous, Gao investigated effect of shearing and thermal degradation. He found that they have negative impacts on viscosity of $\operatorname{HPAM}(\mathrm{Gao} 2013)$.

In the last years, a new technique was introduced to enhanced oil recovery which was ionic liquids flooding as a part of chemical flooding. Ionic liquids are salts with a melting point below $100{ }^{\circ} \mathrm{C}(212$ ${ }^{\circ} \mathrm{F}$ ) and have recently attracted considerable attention as possible alternatives to conventional organic solvents in a variety of synthetic, catalytic, and electrochemical applications. Ionic liquids are salts that typically consist of organic cations like imidazolium, or pyridinium cation and inorganic anions such as halides, [AlCl4]-, [BF4]-, or [PF6]-. They are often found as liquids at room temperature (collective ; Dai, DePaoli et al. 2003; Domańska 2005; Johnson 2007; Simoni, Lin et al. 2008). The principle advantages of ionic liquids are negligible vapor pressure, non-flammable under ambient conditions, high thermal conductivity, high polarity, high heat capacity, high density, extremely low volatility, high thermal stability, wide temperature range of the liquidity, lowcost, commercial availability, water stability, low toxicity, low environmental impact, noncorrosive and recyclable. The ionic liquids have also the ability to dissolve a wide diversity of materials, including salts, and fats. However, the most important attribute of ionic liquids is the possibility of designing their properties based on the number of cations and anions combination(Domańska 2005; José-Alberto and Jorge 2011).

Benzagouta at el.(Benzagouta, AlNashef et al. 2013) performed several experiments on Ammoeng ionic liquids and Triton X 100. Several Ammoeng ionic liquids were screened to test their suitability 
for use in EOR. The screening was based on solubility in water or brine, e.g. $10 \mathrm{wt} \% \mathrm{NaCl}$ in water. Interfacial tension values measurement were taken for the successful ionic liquids. The studied concentrations of ionic liquids were $0,100,200,500$, and 2,000 ppm. The used surfactant was Triton $\mathrm{X} 100$ and the ionic liquid used after screening was Ammoeng 102. They measured interfacial tension at different temperature ranged from $23^{\circ} \mathrm{C}$ to $90{ }^{\circ} \mathrm{C}$. The interfacial tension measurements were taken. The Saudi crude oil sample was used in this study. They found that most of the Ammoeng ionic liquids were soluble in water and in brine. Also Interfacial tension of Ammoeng 102 in $10 \mathrm{wt} \% \mathrm{NaCl}$ brine is much smaller than that for any other tested Ammoeng ionic liquids. interfacial tension values decrease with the increase of temperature and reach as low as $2.3 \mathrm{mN} / \mathrm{m}$ at reservoir temperature. The interfacial tension values decrease with the increase of ionic liquid concentration at the same temperature. Interfacial tension value of the ionic liquid in brine is much smaller than that in deionized water at the same conditions. They concluded that some of the tested ionic liquids gave very high interfacial tension values, even at high concentration of the ionic liquid. Moreover, the measured interfacial tension increased with the increase of temperature. In all cases, the interfacial tension values decreased with the increase of ionic liquid concentration. Ammoeng 102 gave the least interfacial tension values, which decreased with the increase of temperature.

Bin Dahbag and others(Bin-Dahbag 2013; Bin-Dahbag, Al-Quraishi et al. 2014; M. S. Bin-Dahbag, A. A. Al-Quraishi et al. 2014) performed a screening process on several ionic liquids, based on ionic liquid solubility in brine at different salinities and distilled water, thermal stability and their effectiveness in lowering aqueous-oleic phases interfacial tension at different temperatures. These used brines are brine I $(100 \% \mathrm{NaCl})$, brine II $\left(95 \% \mathrm{NaCl}\right.$ and $\left.5 \% \mathrm{CaCl}_{2}\right)$, and brine III $(83 \% \mathrm{NaCl}$ and $17 \% \mathrm{CaCl}_{2}$ ). They found that Ammoeng 102 was the only ionic liquid soluble in all aqueous phases tested with significant ability to lower interfacial tension at increasing temperatures. The obtained results prove that Ammoeng 102 possesses high capability to lower surface tensions and this can be related to its cationic nature with positive charges that are neutralized by the brine negatively charged ions leading to easier accumulation of ionic liquids molecules at the oil-brine interface, causing more interfacial tension reduction. They perfomermed several flooding runs using IL. They concloded that an injection of IL as a slug at starting of flooding is better than ijection of IL as a tertiary flooding.

In oil industry, sometimes more than one method are performed together to increase the efficiency of crude oil recovery because each method has its mechanism in increasing the efficiency of the crude oil recovery. Therefore, a combination of flooding processes is performed. In this study, solution of ionic liquids will was at optimum concentrations based on previous studies(Bin-Dahbag 2013,Bin-Dahbag, Al-Quraishi et al. 2014; M. S. Bin-Dahbag, A. A. Al-Quraishi et al. 2014). In addition, polymers solutions were prepared at different concentrations, salinities. Different flooding scenarios will be performed using polymer buffers in different scenarios to study factors affecting on ionic liquid flooding.

\section{EXPERIMENTAL WORK}

\subsection{Materials}

Many chemicals were used in this study to prepare brine, ionic liquid solution and polymer solutions. The following chemicals were used in the experimental work:

- Fresh water $\left(\mathrm{H}_{2} \mathrm{O}\right)$

To insure accurate concentrations of both saline water and ionic liquid and polymersolutions, fresh water was used as a solvent in preparing of these solutions. This water was produced from tap water using filtration machine.

- Sodium Chloride $(\mathrm{NaCl})$

- Calcium Chloride $(\mathrm{CaCl} 2)$

The main anion dissolved in the brine is chloride $\left(\mathrm{Cl}^{-}\right)$, while the main cations are Sodium $\left(\mathrm{Na}^{+}\right)$and Calcium $\left(\mathrm{Ca}^{++}\right)$(Basyoni 2009). These ions are dissolved in the brine with many other ions (cations like potassium $\left(\mathrm{K}^{+}\right)$and Magnesium $\left(\mathrm{Mg}^{++}\right)$and anions like Bicarbonates $\left(\mathrm{HCO}_{3}{ }^{-}\right)$and Sulfates $\left(\mathrm{SO}_{4}{ }^{--}\right.$ ). The total summation of these ions called TDS. The ions other than Sodium $\left(\mathrm{Na}^{+}\right)$, Calcium $\left(\mathrm{Ca}^{++}\right)$ and chloride $\left(\mathrm{Cl}^{-}\right)$, represent a very small amount in the total dissolved solid(Basyoni 2009). Because of that, they were neglected during preparation of the brine. High purity Sodium Chloride and Calcium Chloride were dissolved in fresh water to simulate the brine in Saudi Arabia. 
- Tetra-alkyl ammonium sulfate

Tetra-alkyl ammonium sulfate commercially is known as Ammoeng 102. It's an ammonium based ionic liquid and soluble in distilled water and brine.

- Partially Hydrolyzed Polyacrylamide

Partially hydrolyzed polyacrylamide (HPAM) is one of the polyacrylamide group. HPAM is a synthetic polymer and the mostly use in polymer flooding. It's characterized by heavy molecular weight, availability and solubility in fresh water and brines.

- Crude oil

The used crude is a Saudi medium crude oil. A density of $28^{\circ}$ API and a viscosity of $23 \mathrm{cp}$ at ambient condition characterize it. This crude can classified as medium to heavy crude. It tends to be an asphaltic crude.

- Core samples

Berea sandstone core samples were used for flooding tests. Table1summarizes rock samples petrophysical properties.

Table1. Dimensions, weights and petrophysical properties of the used cyliderical core samples.

\begin{tabular}{|c|c|c|c|c|c|c|c|c|}
\hline $\begin{array}{c}\text { Run } \\
\text { code }\end{array}$ & $\mathbf{D}, \mathbf{c m}$ & $\mathbf{L}, \mathbf{c m}$ & $\mathbf{V}_{\mathbf{B}}, \mathbf{c m}^{\mathbf{3}}$ & $\mathbf{W}_{\mathbf{d}}, \mathbf{g m}$ & $\mathbf{W}_{\mathbf{s}}, \mathbf{g m}$ & $\mathbf{V}_{\mathbf{P}}, \mathbf{c m}^{\mathbf{3}}$ & $\boldsymbol{\varphi}, \mathbf{\%}$ & $\mathbf{k}, \mathbf{m d}$ \\
\hline$\# 3$ & 3.78 & 11.82 & 132.65 & 282.0 & 311.7 & 25.77 & 19.43 & 233 \\
\hline$\# 9$ & 3.84 & 10.72 & 124.15 & 258.2 & 285.3 & 23.51 & 18.94 & 221 \\
\hline$\# 10$ & 3.80 & 10.25 & 115.89 & 243.4 & 269.1 & 22.30 & 19.24 & 216 \\
\hline$\# 11$ & 3.85 & 11.26 & 131.03 & 271.8 & 301.6 & 25.86 & 19.73 & 202 \\
\hline$\# 12$ & 3.78 & 11.83 & 132.76 & 279.7 & 310.1 & 26.38 & 19.87 & 210 \\
\hline$\# 13$ & 3.69 & 12.03 & 128.60 & 259.7 & 287.6 & 24.21 & 18.82 & 211 \\
\hline$\# 14$ & 3.80 & 11.45 & 129.52 & 273.3 & 301.6 & 24.56 & 18.96 & 209 \\
\hline$\# 15$ & 3.81 & 11.31 & 128.61 & 282.0 & 311.2 & 25.34 & 19.70 & 212 \\
\hline
\end{tabular}

\subsection{Flooding Unit}

A Core Flooding System CFS-200 was used to measure the permeability and for displacement. A schematic of the core setup used is shown in Figure2. It consists of Isco dual positive displacement pump, a hassler type core holder made of stainless steel capable of housing up to 12 in long plug samples with 1.5 inch diameter. The core holder is rated to $10,000 \mathrm{psi}$ confining pressure and temperature of $177^{\circ} \mathrm{C}\left(350^{\circ} \mathrm{F}\right)$. The core holder is connected to three Floating Piston Accumulators (FPAs) connected in parallel and used to inject brine, crude oil and ionic liquid and polymer solutions. Dome type back pressure regulator is connected to core outlet to control reservoir pore pressure and a network of steel piping and manual and air actuated valves are used to direct and control the fluids flow. System temperature was attained using heating tapes connected by temperature controller. System pressure across the core holder is measured using several line and differential transducers all connected to data acquisition for data logging throughout the experiment.

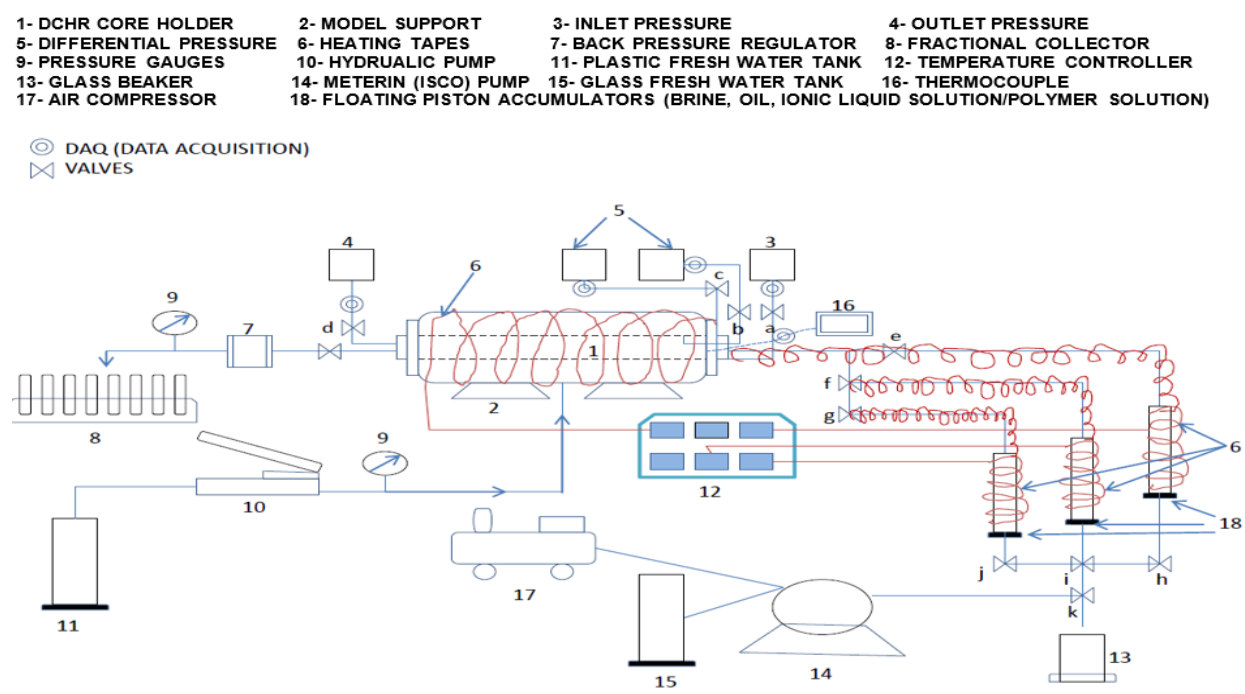

Figure2. Schematic diagram of core flooding system CFS-200. 


\subsection{Solutions Preparation}

To simulate brine, Sodium Chloride and Calcium Chloride were dissolved in fresh water at $20 \%$ by weight TDS. The fractions of Sodium Chloride and Calcium Chloride were 0.83 and 0.17 by weight respectively. Ionic liquid solution was prepared at $500 \mathrm{ppm}$ Ammoeng 102 concentration dissolved in a part of the prepared brine. In addition, three polymer solutions were prepared with different salinities and polymer concentrations. Table 2 summarizes the properties of the prepared solutions in this study.

Table2. Prepared solutions properties.

\begin{tabular}{|c|c|c|c|}
\hline Solution & Salinity, \% & $\begin{array}{c}\text { IL concentration, } \\
\text { ppm }\end{array}$ & $\begin{array}{c}\text { HPAM } \\
\text { concentration, ppm }\end{array}$ \\
\hline Brine & 20 & 0 & 0 \\
\hline $\begin{array}{c}\text { Ionic liquid } \\
\text { solution }\end{array}$ & 20 (IL dissolved in 20\% salinity brine) & 500 & 0 \\
\hline $\begin{array}{c}\text { Polymer } \\
\text { solution I }\end{array}$ & 0 (HPAM dissolved in fresh water) & 0 & 500 \\
\hline $\begin{array}{c}\text { Polymer } \\
\text { solution II }\end{array}$ & 20 (HPAM dissolved in 20\% salinity brine) & 0 & 1,000 \\
\hline $\begin{array}{c}\text { Polymer } \\
\text { solution III }\end{array}$ & 0 (HPAM dissolved in fresh water) & 0 & 500 \\
\hline
\end{tabular}

\subsection{Flooding Runs}

Core samples were prepared with appropriate dimension, dried, and weighed dry and saturated with brine, then weighed saturated. The porosity of the core samples was estimated. For each run, reservoir conditions were applied. The confining pressure was 5,000 psi approximately while the pore pressure was adjusted to be above 2,000 psi. The core samples were exposed to brine flow at different rates before drainage cycle to estimate cores absolute permeability. After that, drainage processes started and continued until water production stopped. Crude oil was injected at rate of $1 \mathrm{~cm}^{3} / \mathrm{min}$. Table shows the reservoir temperatures and summarizes flooding runs parameters. This table illustrates the different flooding scenarios. Firstly, a flooding run (\#9) was conducted using a slug size of 0.4 PV IL, which injected from the beginning and followed by brine injection. In next flooding runs, buffer of polymer were injected at different polymer slug sizes, polymer concentrations, salinities as shown in Table3. Further flooding runs were performed at different temperatures to study of effect of temperature. Injection rate during imbibition process was $0.25 \mathrm{~cm}^{3} / \mathrm{min}$. Finally an additional flooding was conducted at $1.0 \mathrm{~cm}^{3} / \mathrm{min}$ during imbibition cycle.

Table3. Summery of flooding runs.

\begin{tabular}{|c|c|c|c|c|c|}
\hline Run code & $\mathbf{Q}, \mathbf{~ c m}^{\mathbf{3}} / \mathbf{m i n}$ & $\begin{array}{c}\mathbf{T}, \\
\left.{ }^{\mathbf{F}} \mathbf{(} \mathbf{} \mathbf{C}\right)\end{array}$ & $\begin{array}{c}\text { HPAM solution } \\
\text { PV }\end{array}$ & PC, ppm & $\begin{array}{c}\text { HPAM solution } \\
\text { salinity, \% }\end{array}$ \\
\hline$\# 3$ & 0.25 & $140(60)$ & \multicolumn{2}{|c|}{ Only IL was injected with polymer buffer } \\
\hline$\# 9$ & 0.25 & $140(60)$ & 0.4 & 500 & 0 \\
\hline$\# 10$ & 0.25 & $140(60)$ & 0.4 & 500 & 20 \\
\hline$\# 11$ & 0.25 & $140(60)$ & 0.3 & 500 & 0 \\
\hline$\# 12$ & 0.25 & $140(60)$ & 0.4 & 1,000 & 0 \\
\hline$\# 13$ & 0.25 & $167(75)$ & 0.4 & 500 & 0 \\
\hline$\# 14$ & 0.25 & $194(90)$ & 0.4 & 500 & 0 \\
\hline$\# 15$ & 1.00 & $194(90)$ & 0.4 & 500 & 0 \\
\hline
\end{tabular}

\section{RESUltS AND Discussions}

\subsection{Effect of Using of Polymer Buffer on Oil Recovery Using Ionic Liquid}

In run \#9, a PV of $40 \%$ as a polymer buffer at a concentration of $500 \mathrm{ppm}$ in fresh water was injected after injection of a $0.4 \mathrm{PV}$ from ionic liquid solution as a slug at a concentration of $500 \mathrm{ppm}$ in $20 \%$ salinity brine. Comparing the recoveries versus injected pore volumes for both run \#3 and run \#9 where in run \#3 only a slug size of $40 \%$ from ionic liquid at a concentration of $500 \mathrm{ppm}$ in $20 \%$ salinity brine followed directly by $20 \%$ salinity brine. This is shown in figure 3 In this figure, three distinct stages are clear. In the first stage, in both run \#3 and run \#9, the injected slug size still less than $40 \%$ from pore volume, in other word, the injected fluid is the ionic liquid solution. In addition, in this stage, the breakthrough is not reached and the core samples have nearly equalpetrophysical 
porosities. Therefore, the recoveries were nearly the same. In the second stage, lower oil produced in run \#9 due to effect of zero salinity polymer solution on the efficiency of the ionic liquid. The ionic liquid has low efficiency in reducing interfacial tension in lower salinity media. Bin Dahbag et al.(Bin-Dahbag 2013; Bin-Dahbag, Al-Quraishi et al. 2014; M. S. Bin-Dahbag, A. A. Al-Quraishi et al. 2014) stated that the ionic liquid reduces the interfacial tension in when the salinity is high. At the beginning of the second stage, in both run \#3 and run \#9, breakthrough happens and maximum oil recovery is reached in run \#3, while oil recovery is gradually decreases to very low values in run \#9. At starting of third stage, effect of polymer solution viscosity started. The oil recovery efficiency is affected by the displacing fluid viscosity and the majority of the recovered oil in this stage is due to improvedmobility ratio. The polymer solution is characterized by high viscosity, especially when there are no salts in the polymer solution as it is mentioned previously. This results in lower mobility ratio between the displacing fluid to the displaced fluid. Figure4 shows how polymer solution injection influenced on mobility ration. Polymer solution had high viscosity; therefore, oil recovery was enhanced.

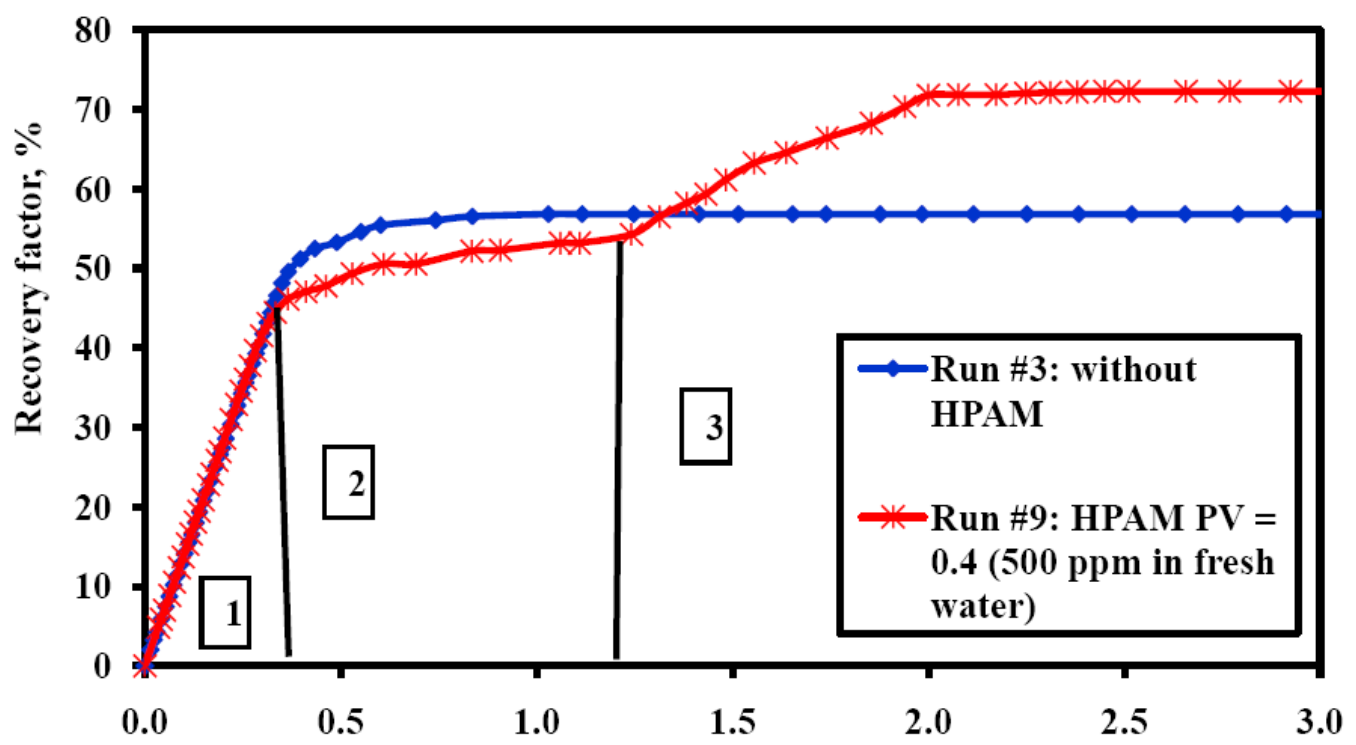

Injected pore volume

Figure3. Effect of polymer injection on oil recovery efficiency using ionic liquid.

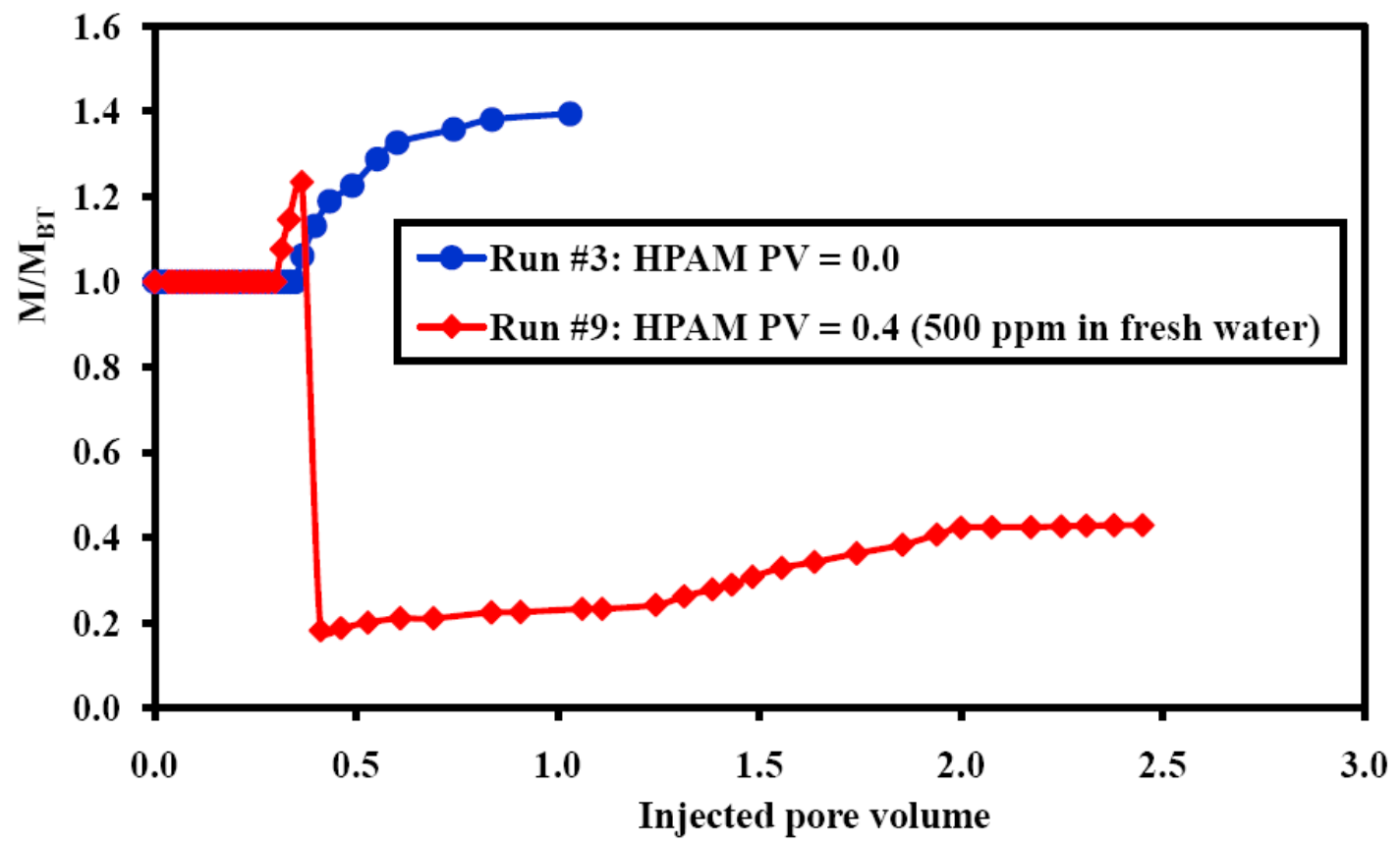

Figure4. Effect of polymer injection on mobility ratio. 


\subsection{Salinity Effect on Polymer Efficiency}

To study the effect of the polymer salinity on the efficiency of the ionic liquid flooding, run \#10 was performed by injection of a slug size of $40 \%$ ionic liquid at a concentration of $500 \mathrm{ppm}$ in $20 \%$ salinity brine followed a polymer slug size of $40 \%$ PV at a concentration of $500 \mathrm{ppm}$ in $20 \%$ salinity followed directly by $20 \%$ salinity brine. Four distinct stages can be remarked in Figure. When the injected pore volume is lower than 0.4 , the displacing fluid was ionic liquid solution in all three runs. This is the first stage shown in Figure5. Also, in this stage, the breakthrough isn't reached. Hence, the recovery factors are the same. At the starting of the second stage, in run $\# 9$, beginning of polymer solution injection at zero salinity affected on the efficiency of the ionic liquid. Since ionic liquid loses its effectiveness in lower salinity. Hence, the oil recovery was lower in run \#9 than run \#3. In run \#10, the salinity of the injected polymer solution was compatible with the salinity of the ionic liquid solution. Both solutions had $20 \%$ salinity, and as result of that, the oil recoveries were nearly identical until the end of this stage. This reflected the effect of polymer solution salinity on the ionic liquid efficiency in reducing the interfacial tension. At beginning of third stage, effect of polymer started earlier when the polymer solution salinity is low. Salinity contents had affected polymer solution viscosity, consequently on mobility ratio as shown in Figure6. Effect of polymer injection needs more time run \#9. Although, injection of low salinity (zero in this study) polymer results in more oil recovery as in run $\# 9$ than that is given by high salinity polymer solution as in run \#10.

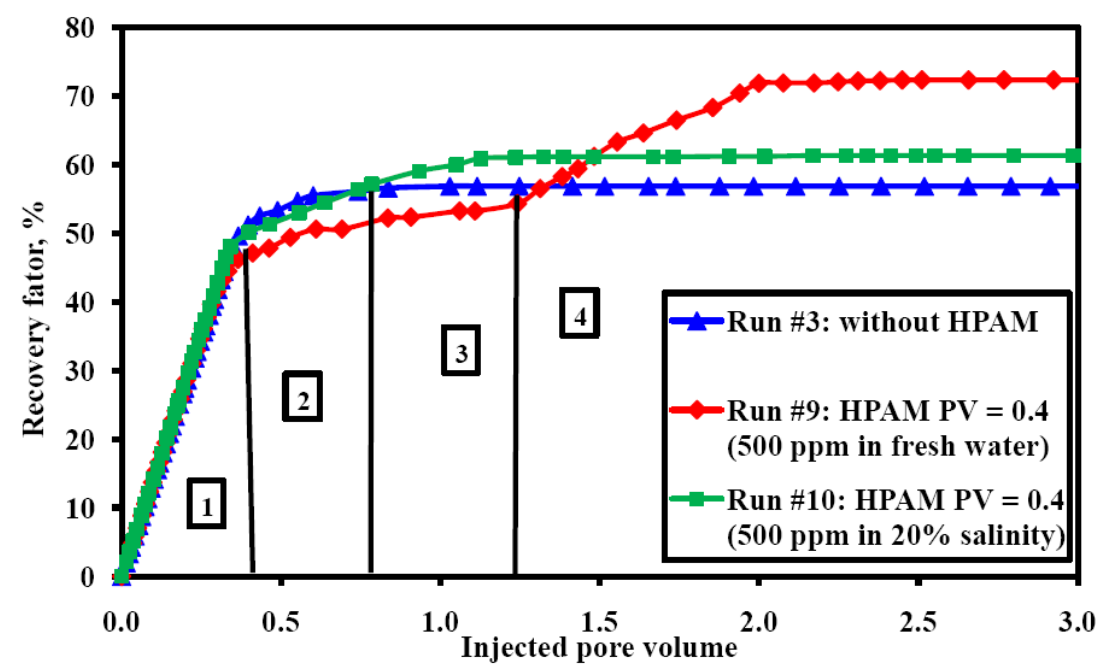

Figure5. Effect of injected polymer solution salinity on polymer efficiency in displacing oil

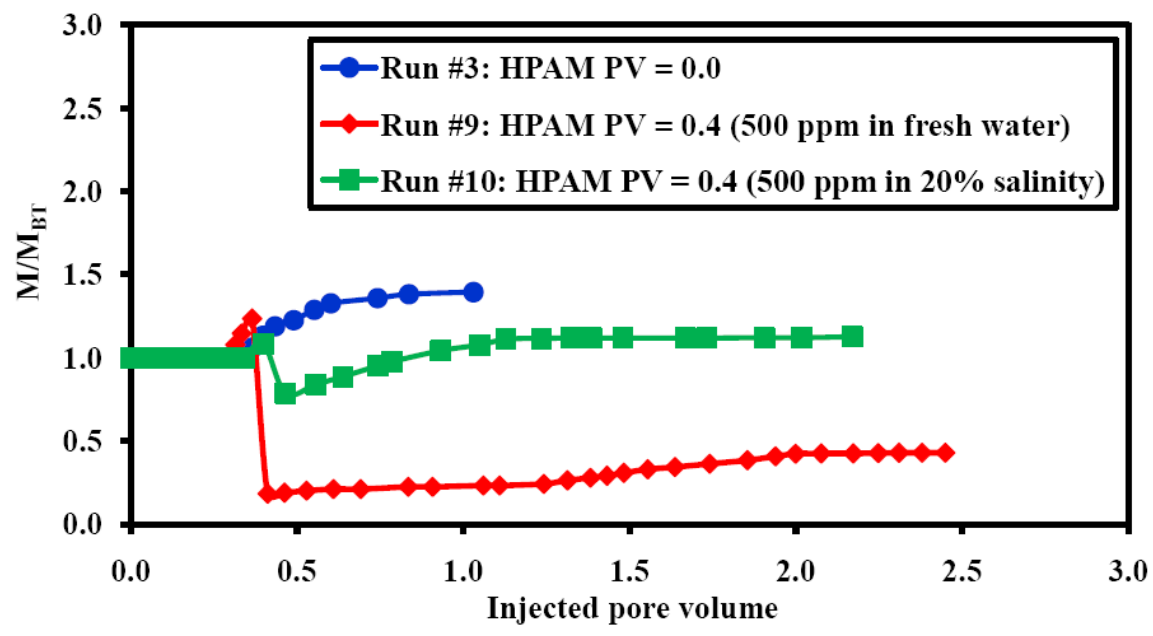

Figure6. Effect of injected polymer solution salinity on mobilty ratio.

\subsection{Polymer Solution Slug Size Effect}

In run \#11, the injected polymer buffer slug size was $30 \%$. The selected polymer solution salinity was zero salinity where the polymer was dissolved in fresh water. The result given in this run is compared with that given by run \#9. In both run \#9 and run \#11, a slug size of 0.4 from ionic liquid solution was injected then a slug size from polymer solution was injected followed by $20 \%$ salinity brine. Only the 
difference is in the polymer slug size. The injected polymer slug sizes were $40 \% \mathrm{PV}$ and $30 \%$ in run $\# 9$ and run \#11 respectively. The oil recovery profiles are corresponded from the starting of the injection to about injected pore volume of 1.25. See Figure7. At this point, the effect of improved mobility starts and there is an increasing in oil recovery factor. This oil recovery increasing is faster and shorter when the injected polymer solution slug size is 30\% pore volume. More oil is recovered when the injected polymer solution buffer slug size is $40 \%$ PV. Effect of polymer concentration dilution on mobility ratio is show in figure8.

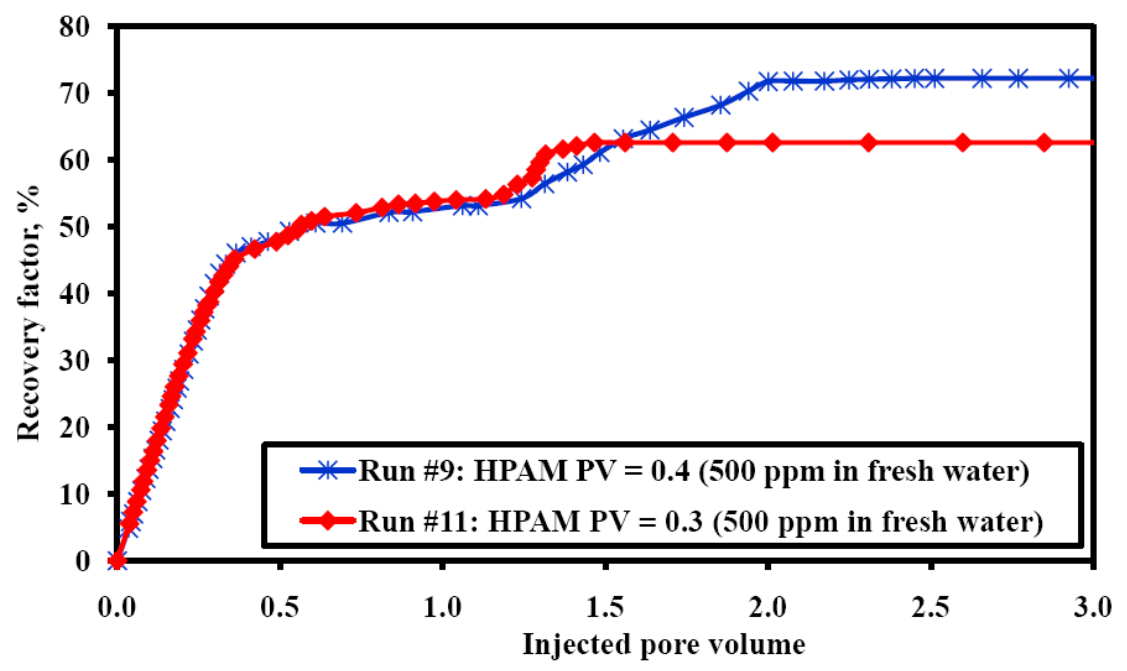

Figure7. Effect of injected polymer solution slug size on polymer efficiency in displacing oil.

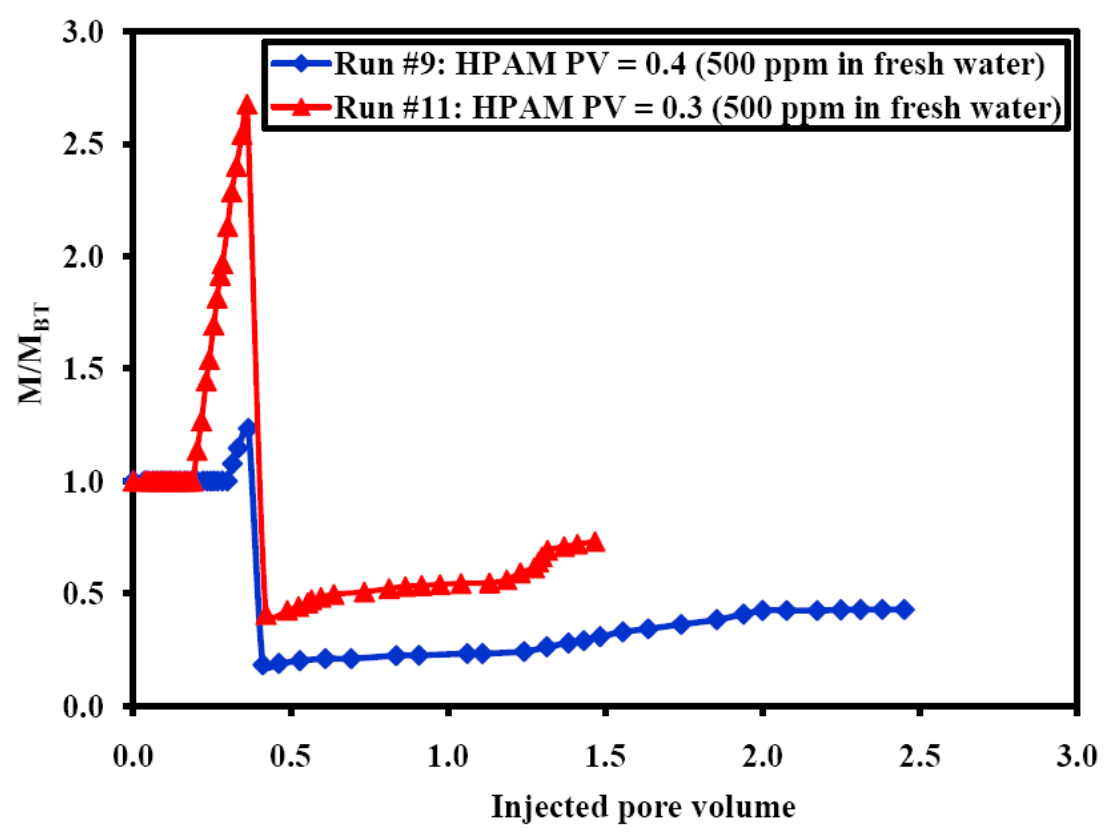

Figure8. Effect of injected polymer solution slug size on mobilty ratio.

\subsection{Polymer Concentration Effect}

Run \#12 was conducted to examine the effect of the polymer concentration. The injected polymer buffer slug size was $40 \% \mathrm{PV}$ at polymer concentration of $1,000 \mathrm{ppm}$ dissolved in fresh water. The result given from this run is compared with that given by run \#9. In both run \#9 and run \#12, a slug size of $40 \%$ from ionic liquid solution was injected then a polymer buffer slug size of $40 \%$ PV of polymer solution was injected followed by $20 \%$ salinity brine. Only the difference is in the polymer concentrations, where two polymer concentrations were examined. They are $500 \mathrm{ppm}$ and 1,000 ppm in run \#9 and run \#12 respectively. The oil recovery factors are the same from the starting of the injection to about injected pore volume of 1.25. See Figure9. At this point, the effect of mobility improvement starts and there is an increasing in oil recovery factor. This oil recovery increasing is faster when the polymer concentration is $500 \mathrm{ppm}$. The oil recovery increases slowly when the polymer concentration is 1,000 . Unlike expected, the polymer concentration of $1,000 \mathrm{ppm}$ results in 
same oil recovery that exists for a polymer concentration of $500 \mathrm{ppm}$. Although, a higher polymer concentration gives a lower displacing fluid mobility due rising of viscosity and consequently, lower mobility ratio. Increasing of polymer solution may plug the pores in the porous media. Mobility ratio was not improved by increasing of polymer concentration. This is attributed to pore plugging due to polymer retention causing reduction of permeability in invaded zone by polymer solution behind oil zone as it is illustrated in Figure10.

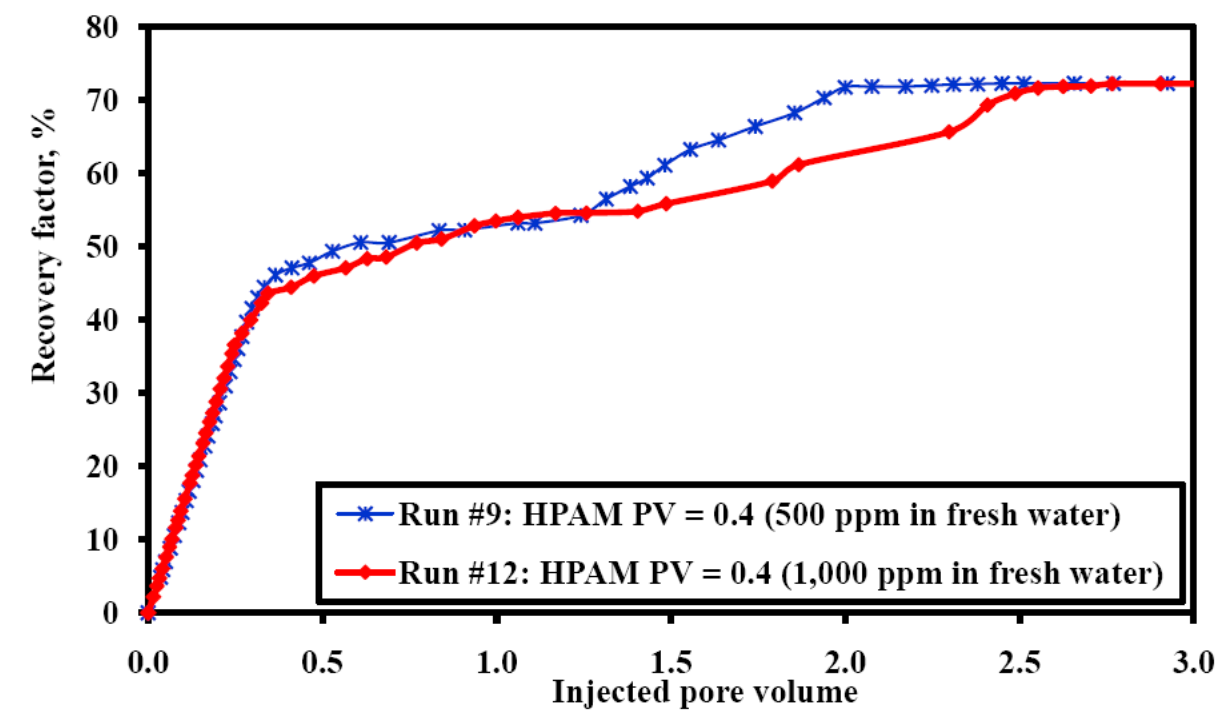

Figure9. Effect of injected polymer concentration on polymer efficiency in displacing oil.

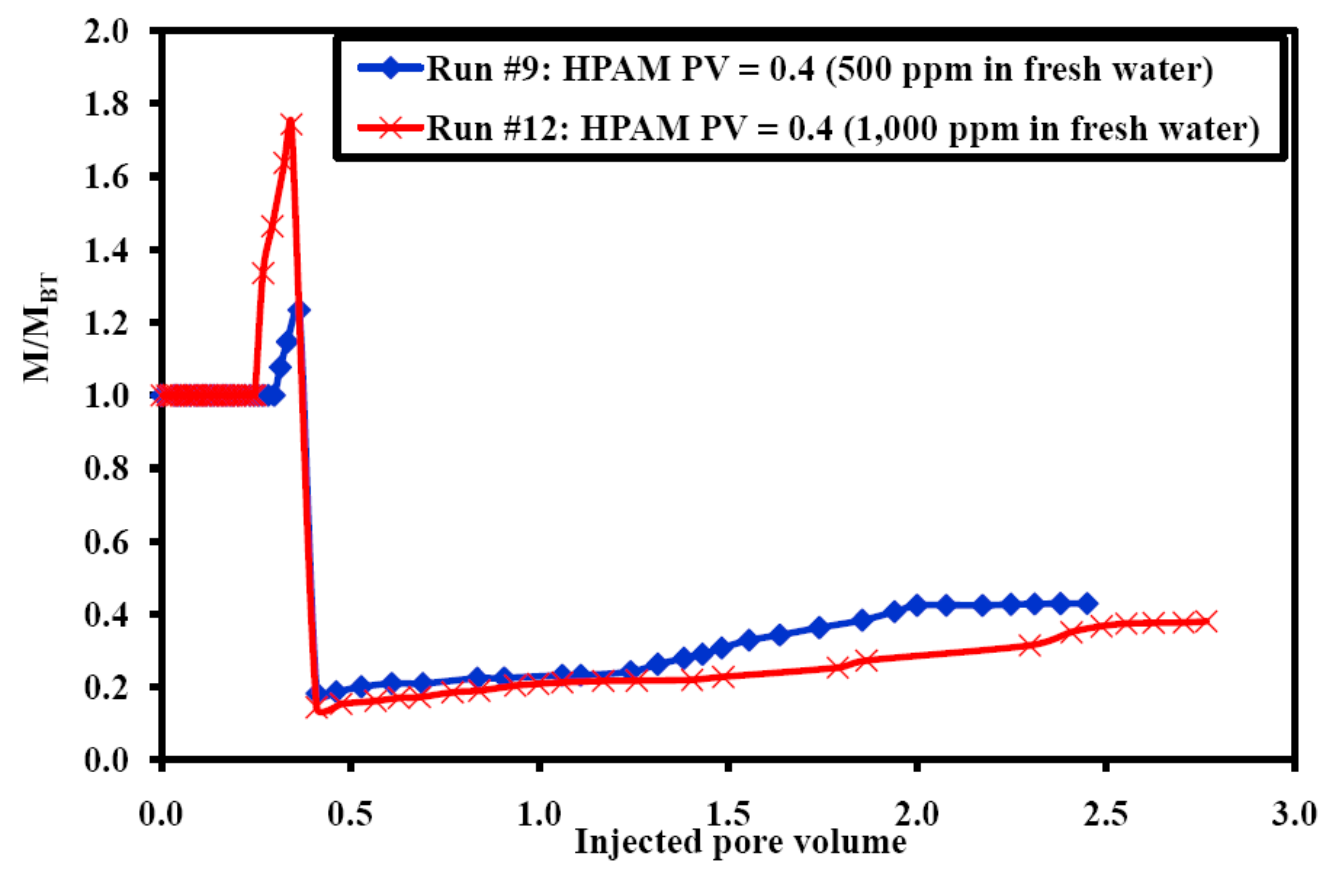

Figure10. Effect of injected polymer concentration on mobilty ratio.

\subsection{Temperature Effect}

To study the efficiency of using polymer buffer on ionic liquid flooding at different temperatures, run $\# 13$ and run \#14 were conducted at temperatures of 75 and $90^{\circ} \mathrm{C}$ respectively. The results given were compared with that given by run $\# 9$, which was conducted at a temperature of $60^{\circ} \mathrm{C}$. The selected ionic solution slug size was $0.4 \mathrm{PV}$ in these runs. Also, slug sizes of $0.4 \mathrm{PV}$ polymer buffer from the polymer solution at polymer concentration of $500 \mathrm{ppm}$ dissolved in fresh water. Nearly, breakthrough happens at the same injected PV for the different temperatures at about of $40 \%$ PV. Figure 11 is an illustration of crude oil recovery for different temperature. Increasing of the temperature result in more recoverable oil after breakthrough but gradually increasing in oil recovery factor versus injected $\mathrm{PV}$ to reach maximum oil recovery in run \#14. At lower temperature, the oil recovery factor is lower than that for higher temperature at relatively early stages of the flood. At certain injected PV, 
additional oil was recovered at the lower temperature. Mobility ratio curves are shown in Figure12. Simultaneous effect of temperature on both oil viscosity and polymer solution viscosity were observed.

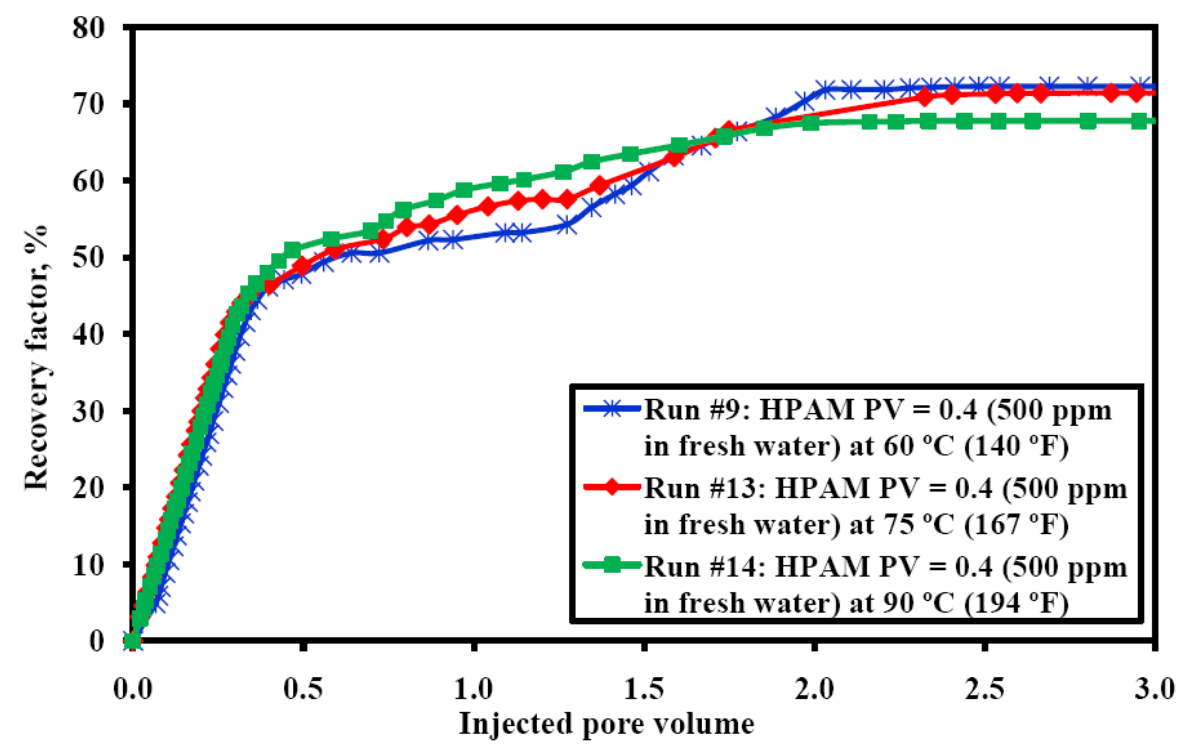

Figure11. Effect of temperature on recovery efficiency of using polymer bufferafter ionic liquid flooding.

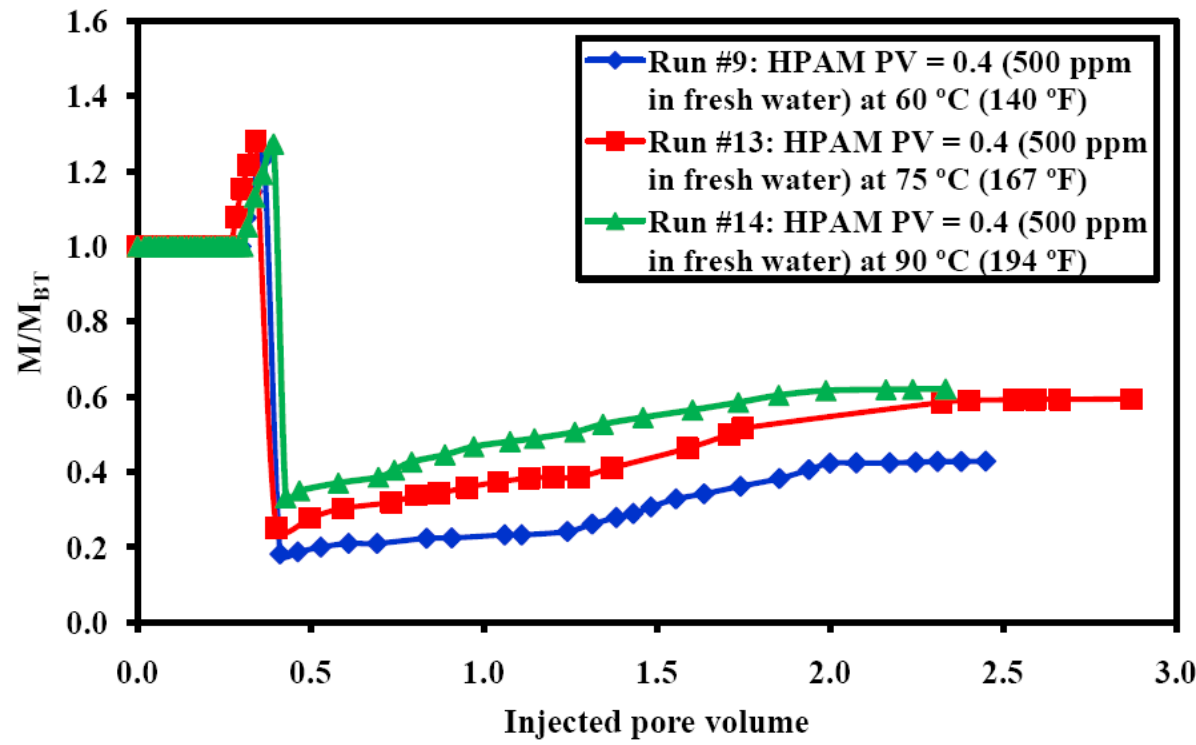

Figure12. Effect of temperature on mobilty ratio.

\subsection{Injection Rate Effect}

To study the effect of injection rate on efficiency of using a polymer buffer and ionic liquid flooding, run \#15 was performed at an injection rate of $1.00 \mathrm{~cm}^{3} / \mathrm{min}$ during imbibition cycle. All other parameters applied in this run were the same parameters applied in run \#14. Comparing the recovery profiles as in Figure 13 shows the effect of injection rate on the oil recovery factor. Early breakthrough happens at injected pore volume of $25 \%$ when the injection flow rate is $1.00 \mathrm{~cm}^{3} / \mathrm{min}$ comparing the case of $0.25 \mathrm{~cm}^{3} / \mathrm{min}$ injection flow rate. This means there was a breakthrough before staring of injection of polymer. The ultimate recovery factors were $67.74 \%$ and $51.54 \%$ when the injected flow rates were 0.25 and $1.00 \mathrm{~cm}^{3} / \mathrm{min}$ respectively. The injected pore volume intervals were shorter when the injection rate is $0.25 \mathrm{~cm}^{3} / \mathrm{min}$ than that in case of the injected flow rate of $1.00 \mathrm{~cm}^{3} / \mathrm{min}$. When the displacing fluids were being injected at high rate, fluid bypass happened and viscous fingering phenomenon perhaps occurred. The displacing fluid leaves more oil in the porous media due to overrun because of high displacing fluid velocity. High polymer solution velocity in porous medium caused mechanical degradation; hence, polymer solution viscosity reduction was encountered. Figure14 is an illustration of mobility curve at injection rates of 0.25 and $1.00 \mathrm{~cm}^{3} / \mathrm{min}$ during imbibition cycles. 


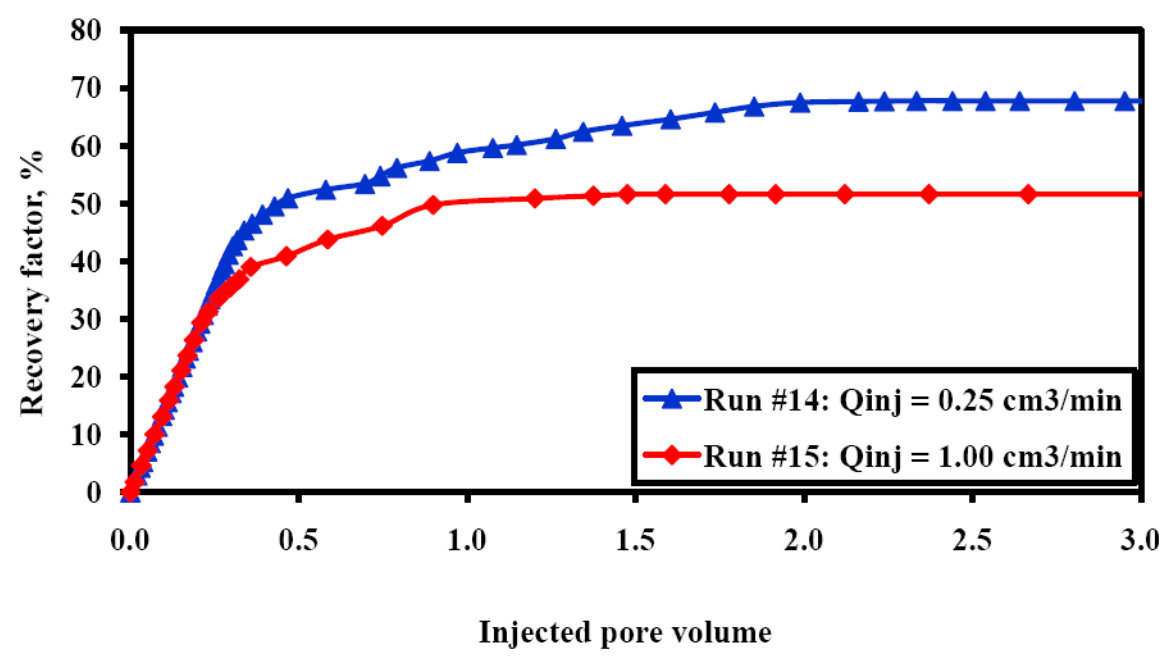

Figure13. Effect of injection rate on recovery efficiency of using polymer buffer after ionic liquid flooding.

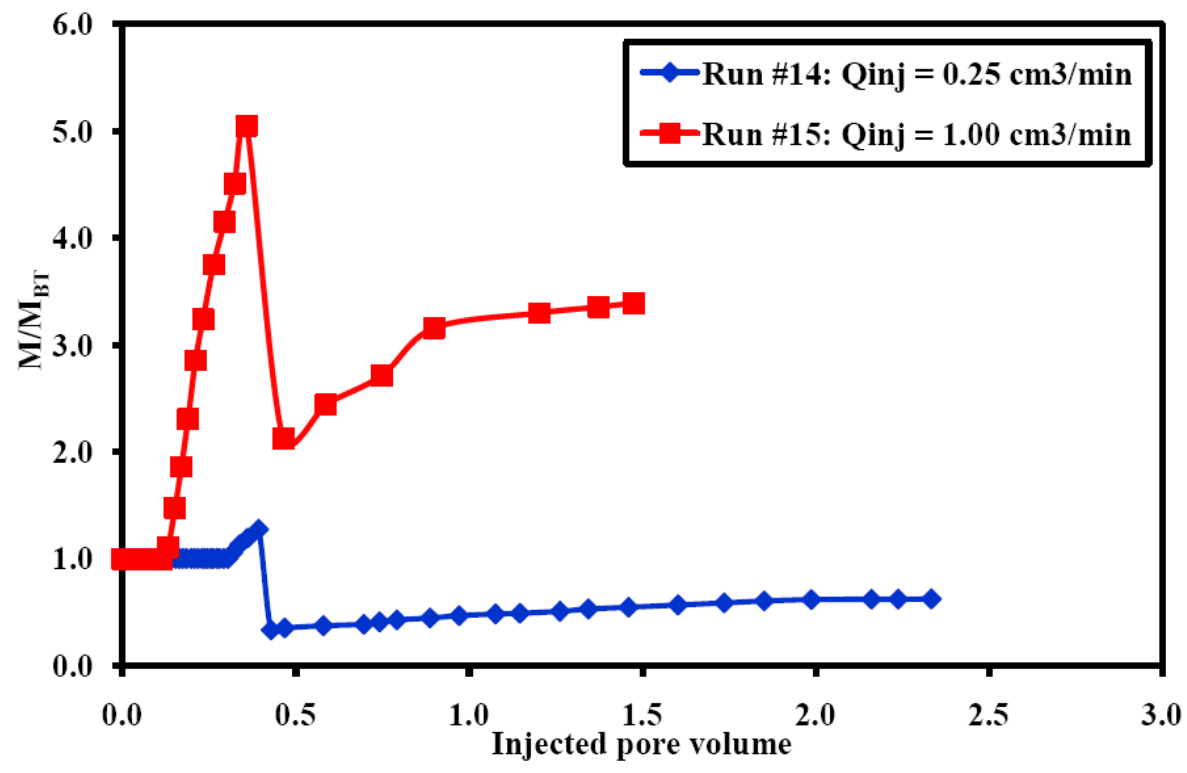

Figure14. Effect of injection rate on mobilty ratio.

\section{Conclusion}

Injection of polymer solution at high salinity leads to a lower ultimate recovery than that for zero salinity solution. This interpreted by effect of salt contents on the polymer molecules and caused mechanical degradation of long molecules chain. This action reduces the apparent viscosity. Increasing of polymer concentration leads to $1,000 \mathrm{ppm}$ approximately same ultimate recovery that is for $500 \mathrm{ppm}$ but at late time. The mechanism behind this outcome is polymer retention due to high polymer concentration result in plugging the pores. Lower oil recovered is obtained when the injected polymer slug size is a 0.3 pore volume than that recovered by injection a polymer slug size is of 0.4 pore volume. For lower inject polymer solution slug size, polymer concentration may diluted when the polymer solution contact with high salinity brine. The efficiency of ionic liquid slug increases at a higher temperature condition due to decreasing of oil viscosity and interfacial tension between ionic liquid solution and crude oil. On the other hand, efficiency of polymer slug decreases with elevating temperature. The reason behind of this result is the thermal degradation of polymer molecules and because of that lowering of polymer solution viscosity. A higher flow injection, a higher shear rate and consequently lower viscosity for polymer solution where the polymer solution behaves as a nonNewtonian dilatant (shear thickening) fluid. Also increasing of polymer velocity gives rise to mechanical degradation of polymer molecules and elongational flow field during flow through a porous medium. The high polymer concentrations should be avoided, because of they cause pore plugging and polymer retention and at the end reduction in permeability. For high temperature condition, may a small increment in polymer concentration leads to balance in decreasing of oil viscosity, and thermal degradation. Investigation shows the mutual influence between polymer and 
ionic liquid solutions using a slug size of law salinity water as a preflush between ionic liquid and polymer solution. Further experiments may be required to study the effectiveness of polymer-ionic liquid flooding in carbonate rocks.

\section{ACKNOWLEDGEMENT}

The authors would like to thank King Saud University for allowing of use Petroleum and Natural Gas Department Labs. In addition, thanks go to the department staff. Special thanks go to Mr. Khalid AlKhidir for providing us HPAM as a powder.

\section{REFERENCES}

[1] Abidin, A., T. Puspasari, et al. (2012). "Polymers for enhanced oil recovery technology." Procedia Chemistry 4: 11-16.

[2] Alvarado, V. and E. Manrique (2010). "Enhanced oil recovery: an update review." Energies 3(9): 1529-1575.

[3] Aronofsky, J. (1952). "Mobility ratio-Its influence on flood patterns during water encroachment." Journal of Petroleum Technology 4(01): 15-24.

[4] Aronofsky, J. and H. Ramey Jr (1956). "Mobility Ratio-Its Influence on Injection or Production Histories in Five-Spot Water Flood." Journal of Petroleum Technology 8(09): 205-210.

[5] Barnes, A. (1962). "The use of a viscous slug to improve waterflood efficiency in a reservoir partially invaded by bottom water." Journal of Petroleum Technology 14(10): 1,147-141,153.

[6] Basyoni, M. H. (2009). "Sediment characteristics, brine chemistry and evolution of Murayr sabkha, Arabian (Persian) Gulf, Saudi Arabia."

[7] Benzagouta, M. S., I. M. AlNashef, et al. (2013). "Ionic liquids as novel surfactants for potential use in enhanced oil recovery." Korean Journal of Chemical Engineering 30(11): 2108-2117

[8] Bin-Dahbag, M. S. (2013). Effect of Ionic Liquids on the Efficiency of Crude Oil Recovery. master, King Saud University.

[9] Bin-Dahbag, M. S., A. A. Al-Quraishi, et al. (2014). "Efficiency of ionic liquids for chemical enhanced oil recovery." Journal of Petroleum Exploration and Production Technology: 1-9.

[10] Caudle, B. and M. Witte (1959). "Production potential changes during sweep-out in a five-spot system." Journal of Petroleum Technology 12(12): 63-65.

[11] collective, A. "Enabling Technologies: Ionic Liquids." Chem.Files vol. 5(6): 23.

[12] Dai, S., D. DePaoli, et al. (2003). "Technical summaries on ionic liquids in chemical processing." Chemical Industry Vision 2020.

[13] Domańska, U. (2005). "Solubilities and thermophysical properties of ionic liquids." Pure and applied chemistry 77(3): 543-557.

[14] Dyes, A., B. Caudle, et al. (1954). "Oil production after breakthrough as influenced by mobility ratio." Journal of Petroleum Technology 6(04): 27-32.

[15] Dykstra, H. and R. Parsons (1950). "The Prediction of Oil Recovery by Water Flood, Secondary Recovery of Oil in the United States, Principle and Practice." Am. Pet. Inst.

[16] Gao, C. (2013). "Viscosity of partially hydrolyzed polyacrylamide under shearing and heat." Journal of Petroleum Exploration and Production Technology 3(3): 203-206.

[17] Johnson, K. E. (2007). "What's an ionic liquid?" Interface-Electrochemical Society 16(1): 38-41.

[18] José-Alberto, M.-H. and A. Jorge (2011). "Current knowledge and potential applications of ionic liquids in the petroleum industry." Ionic liquids: applications and perspectives, InTech: 439-456.

[19] M. S. Bin-Dahbag, A. A. Al-Quraishi, et al. (2014). "Experimental Study of Use of Ionic Liquids in Enhanced Oil Recovery." J Pet Environ Biotechnol 4(165): 2.

[20] Maerker, J. (1975). "Shear degradation of partially hydrolyzed polyacrylamide solutions." Society of Petroleum Engineers Journal 15(04): 311-322.

[21] Moffitt, P. and J. Mitchell (1983). North Burbank Unit Commercial Scale Polymerflood ProjectOsage County, Oklahoma. SPE Production Operations Symposium, Society of Petroleum Engineers.

[22] Mungan, N. (1972). "Shear viscosities of ionic polyacrylamide solutions." Society of Petroleum Engineers Journal 12(06): 469-473 
[23] Muskat, M. (1949). "Physical principles of oil production." McGrawHill Book Co.

[24] Needham, R. B. and P. H. Doe (1987). "Polymer flooding review." Journal of Petroleum Technology 39(12): 1,503-501,507.

[25] Pye, D. J., W. Gogarthy, et al. (1964). "Improved secondary recovery by control of water mobility." J. Pet. Technol.;(United States) 16(8).

[26] Ryles, R. (1988). "Chemical stability limits of water-soluble polymers used in oil recovery processes." SPE reservoir engineering 3(01): 23-34.

[27] Sandiford, B. (1964). "Laboratory and field studies of water floods using polymer solutions to increase oil recoveries." Journal of Petroleum Technology 16(08): 917-922

[28] Simoni, L. D., Y. Lin, et al. (2008). "Modeling liquid-liquid equilibrium of ionic liquid systems with NRTL, electrolyte-NRTL, and UNIQUAC." Industrial \& Engineering Chemistry Research 47(1): 256-272.

[29] Sorbie, K. S. (1991). "Polymer-Improved Oil Recovery." Glasgow and London, Blackie.

[30] Stiles, W. E. (1949). "Use of permeability distribution in water flood calculations." Journal of Petroleum Technology 1(01): 9-13.

[31] Ward, J. and F. D. Martin (1981). "Prediction of viscosity for partially hydrolyzed polyacrylamide solutions in the presence of calcium and magnesium ions." Society of Petroleum Engineers Journal 21(05): 623-631 